\title{
Single-port three-dimensional endoscopic subcutaneous mastectomy for gynaecomastia: an aesthetically superior and novel approach
}

\author{
Chi Wei Mok ${ }^{1,2}$, Jun Xian Jeffrey Hing ${ }^{1,2}$, Su-Ming Tan ${ }^{1,2}$ \\ 'Division of Breast Surgery, Department of Surgery, Changi General Hospital, Singapore 529889, Singapore. \\ ${ }^{2}$ Singhealth Duke-NUS Breast Centre, , Singapore 529889, Singapore.
}

Correspondence to: Dr. Chi Wei Mok, Division of Breast Surgery, Department of Surgery, Changi General Hospital, 2 Simei Street 3, Singapore 529889, Singapore. E-mail: mok.chi.wei@singhealth.com.sg

How to cite this article: Mok CW, Hing JXJ, Tan SM. Single-port three-dimensional endoscopic subcutaneous mastectomy for gynaecomastia: an aesthetically superior and novel approach. Mini-invasive Surg 2019;3:40.

http://dx.doi.org/10.20517/2574-1225.2019.39

Received: 2 Oct 2019 First Decision: 25 Nov 2019 Revised: 27 Nov 2019 Accepted: 17 Dec 2019 Published: 26 Dec 2019

Science Editor: Giulio Belli Copy Editor: Jing-Wen Zhang Production Editor: Jing Yu

\begin{abstract}
Gynaecomastia is a benign clinical condition that can occur in men of all ages, attributed by the proliferation of glandular tissue. Most patients are asymptomatic while symptoms ranging from mild discomfort to severe pain can present in patients with gynaecomastia. In addition to these, this condition may affect the psychological well-being of patients leading to a need for further treatment. Medical treatment of primary gynaecomastia in the form of anti-oestrogen therapy has not been proven to be effective and there is no consensus regarding the drug of choice or optimal duration of treatment. Surgical treatment is usually the standard treatment in primary gynaecomastia. There have been various techniques described in the literature with the aim of restoring a pleasant chest shape with limited scar on incision. Most of the techniques however involve the use of a peri-areolar or a Wise pattern incision, which can be obvious, especially in patients with a tendency to scar badly. The authors describe a novel approach, whereby a single-port endoscopic subcutaneous mastectomy using the three-dimensional endoscopic system with incision placed along the anterior axillary line was performed for a patient with gynaecomastia and thereby conferring excellent aesthetic outcomes.
\end{abstract}

Keywords: Gynaecomastia, subcutaneous mastectomy, endoscopic, endoscopic-assisted, three-dimensional, single port, insufflation

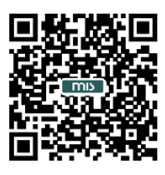




\section{INTRODUCTION}

Surgical techniques in gynaecomastia treatment have evolved over the years towards less invasive approaches such as liposuction ${ }^{[1]}$. However, in patients with larger amount of tissue or ptotic breast, subcutaneous mastectomy is still more effective in removing excess glandular tissue ${ }^{[2]}$. The downside to subcutaneous mastectomy are the resulting large, long and often unsightly scars ${ }^{[3]}$. Endoscopic subcutaneous mastectomy has been described in the literature ${ }^{[4,5]}$ where it is commonly performed via three incisions along the mid-axillary line or a single incision in the axilla and the specimen will be morcellated and suctioned out thereafter. Single-port nipple-sparing mastectomy using three-dimensional (3D) endoscopic system in the management of breast cancer was recently reported ${ }^{[6]}$ and the authors describe the advantage of enhanced $3 \mathrm{D}$ visualisation in the conduct of the operation, allowing precise plane recognition and dissection. In this article, the authors describe the use of single-port 3D endoscopicassisted subcutaneous mastectomy in the management of gynaecomastia.

\section{TECHNIQUE}

\section{Preoperative markings and positioning}

Preoperative markings were performed with the patient in standing and sitting position [Figures 1 and 2]. Extent of dissection was determined with comparison to the contralateral (non-gynaecomastia) side. Under general anaesthesia, patient was then placed in a supine position with ipsilateral arm abducted at $90^{\circ}$ [Figure 3]. The ipsilateral shoulder was then elevated to $30^{\circ}$ to facilitate access for the operation.

\section{Tumescent injection}

Methylene blue gel was used to mark the extent of dissection to aid in identification during subsequent endoscopic dissection. A saline solution containing lignocaine $0.05 \%$ and epinephrine 1:1,000,000 was injected subcutaneously into the whole breast to minimise bleeding.

\section{Skin flap dissection}

Following that, a $3-\mathrm{cm}$ incision was made over the extra-mammary region near the anterior axillary line at the level of nipple areolar complex (NAC). A working space of 4-5 $\mathrm{cm}$ was created by dissecting the subcutaneous flap under direct vision to allow subsequent placement of the single port. After creation of working space, subcutaneous tunnelling/blunt dissection of the anterior skin flap with Metzenbaum scissors was performed to aid in subsequent skin flap dissection. Following that, posterior dissection of breast parenchyma off pectoralis major fascia was performed under endoscopic guidance with endoscopic vein harvester [Figure 4]. Thereafter, the single port was placed with $\mathrm{CO}_{2}$ insufflation kept at a pressure of $8 \mathrm{mmHg}$. A $30^{\circ}$ 10-mm diameter camera TIPCAM 1 S- 3D VIDEO Endoscope (KARL STORZ, Germany), 5-mm laparoscopic Metzenbaum scissors, curved (Applied Medical, USA) and 5-mm laparoscopic grasping forceps were used to conduct the operation [Figure 5].

\section{Endoscopic subcutaneous mastectomy}

Endoscopic dissection commenced from superficial skin flaps in all quadrants with the septa between skin flap and parenchyma dissected using laparoscopic Metzenbaum scissors [Figures 6 and 7]. During skin flap dissection, a $30^{\circ}$ upward facing $3 \mathrm{D}$ endoscope with reverse imaging was used to produce a clear $3 \mathrm{D}$ image. The angle and field of vision could be adjusted with upward, downward or reverse motion of the image by the $3 \mathrm{D}$ endoscope when deemed necessary. Tissue beneath the NAC were intentionally left thicker to prevent nipple retraction as well as preserve the blood supply to NAC, thereby reducing the risk of NAC necrosis [Figure 8]. With 3D visualisation, blood vessels could be clearly visualised and hence preserved [Figure 9]. After completion of superficial skin flap dissection, peripheral dissection was carried 

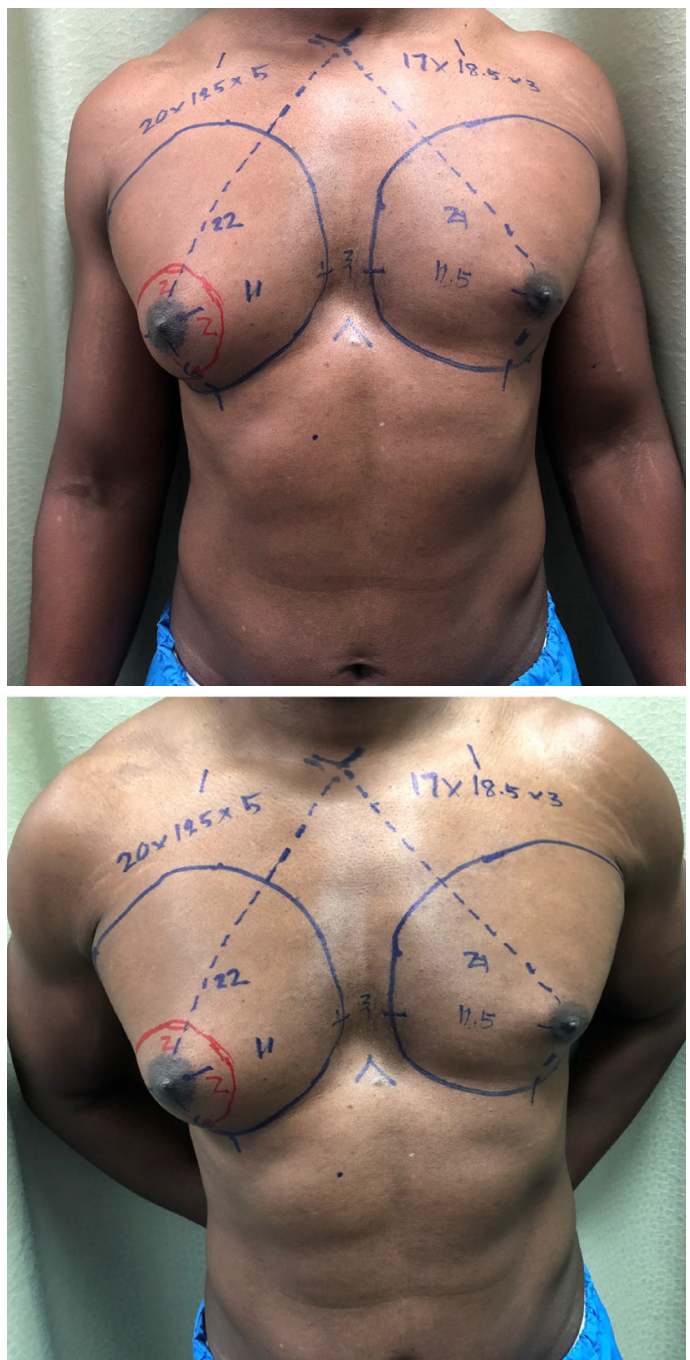

Figure 1. Preoperative front views showing preoperative markings and right gynaecomastia. Extent of planned dissection was marked out (as shown by red markings)

out by retracting breast tissue to create sufficient working space and extent of dissection was based on preoperative markings and intraoperative blue dye gel [Figure 10]. After the completion of dissection, the entire breast specimen was removed intact through the incision and haemostasis secured. A three-point fixation of the NAC to underlying pectoralis major fascia was then performed with absorbable stitches. A closed suction drain was placed.

\section{Postoperative outcomes}

Patient was discharged the next day and drain subsequently removed on Postoperative Day 5. Following the surgery, the patient was seen a month after surgery with excellent aesthetic outcomes [Figures 11-13].

\section{CONCLUSION}

Single-port 3D endoscopic subcutaneous mastectomy is a novel and aesthetically superior approach for the treatment of gynaecomastia if compared to conventional methods. 

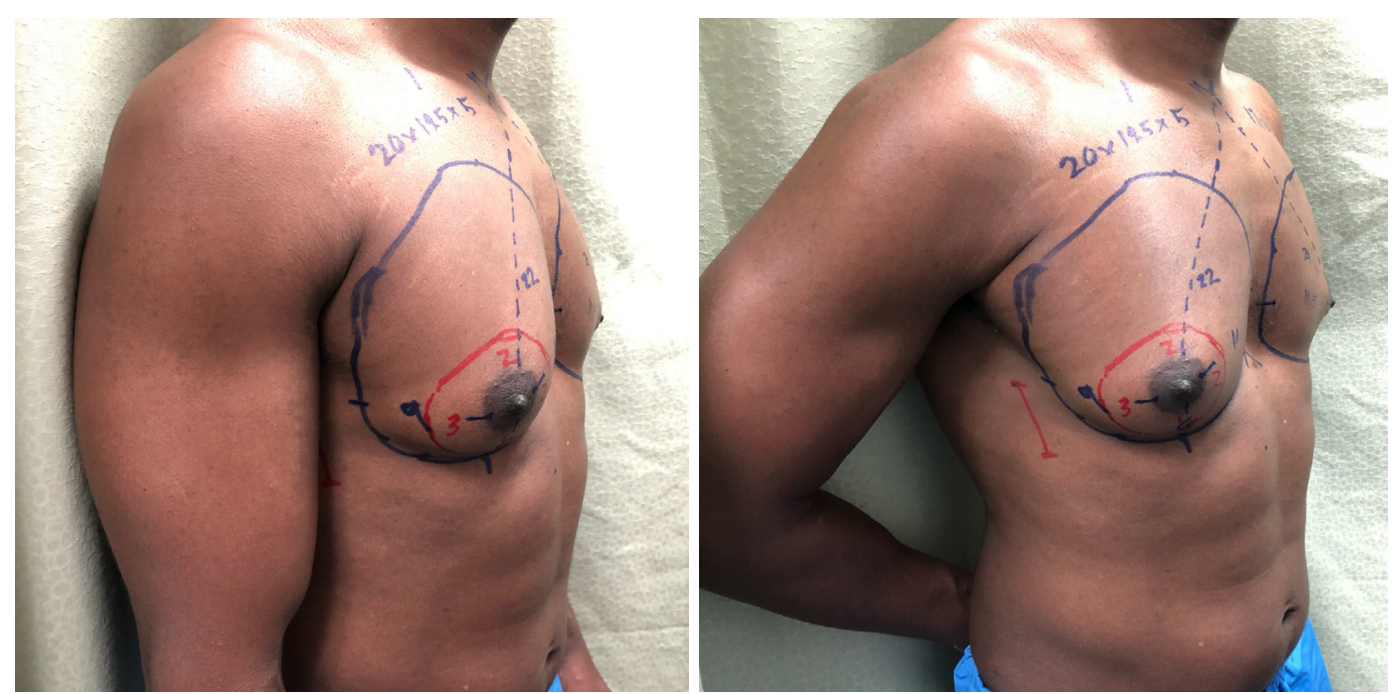

Figure 2. Preoperative lateral views showing preoperative markings and right gynaecomastia. Extent of planned dissection was marked out (as shown by red markings)

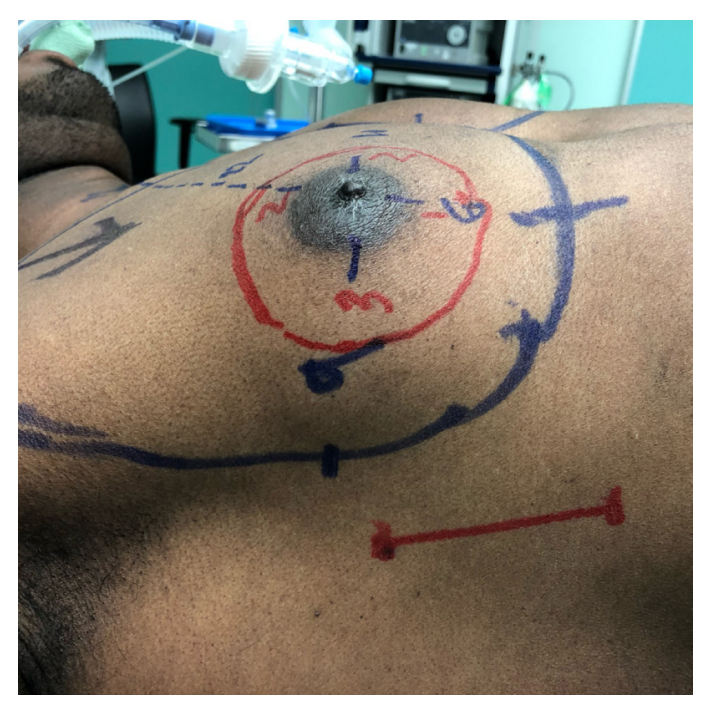

Figure 3. On-table view showing the planned incision

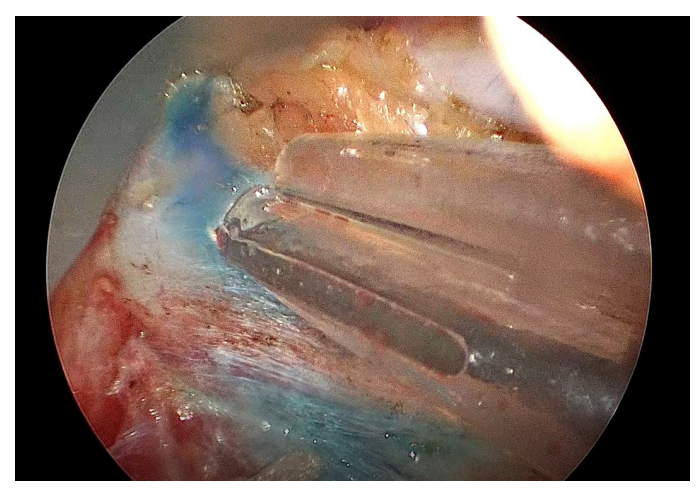

Figure 4. Endoscopic view showing the dissection of breast parenchyma off pectoralis major fascia 


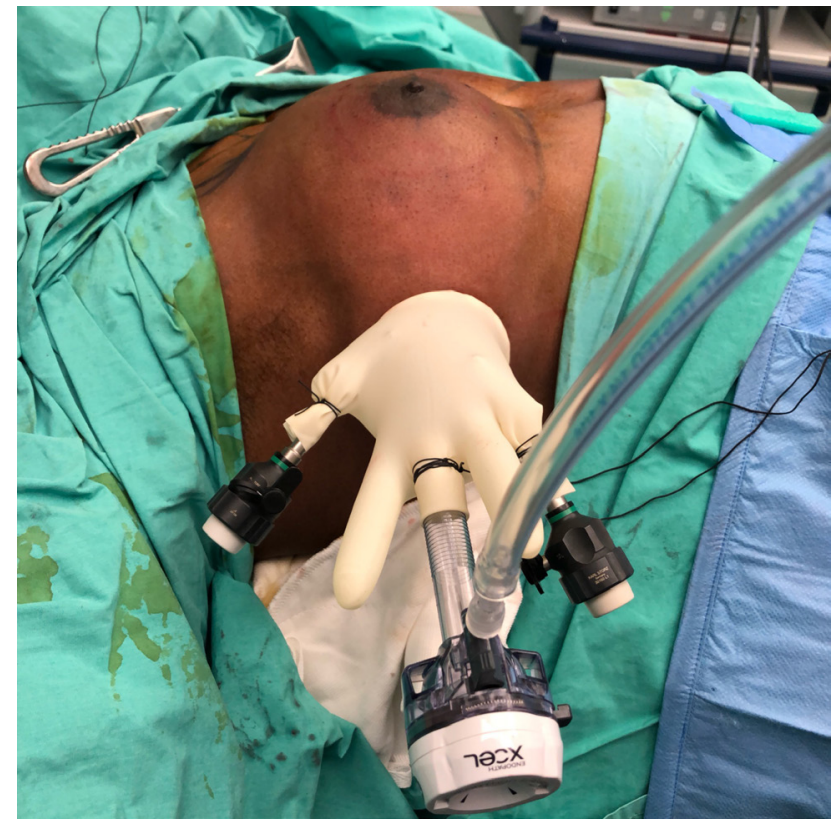

Figure 5. On-table view demonstrating placement of single port and instruments before commencement of endoscopic subcutaneous mastectomy

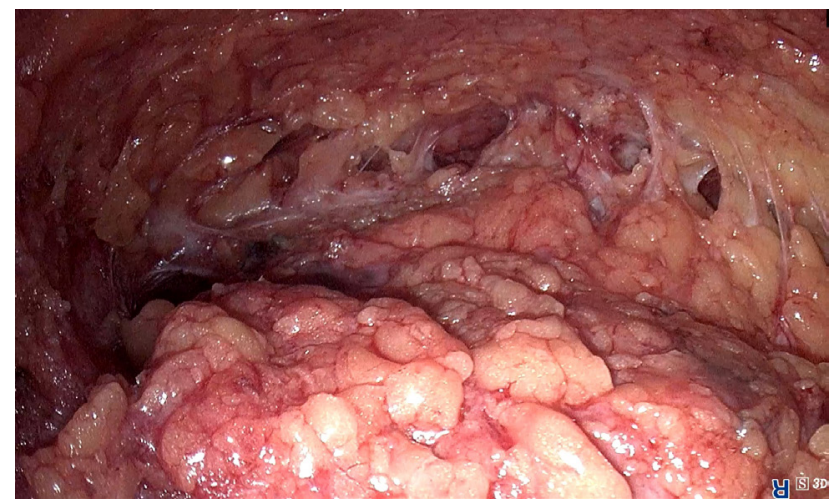

Figure 6. Endoscopic view after $\mathrm{CO}_{2}$ insufflation demonstrating fibrous septa between skin flap and breast parenchyma

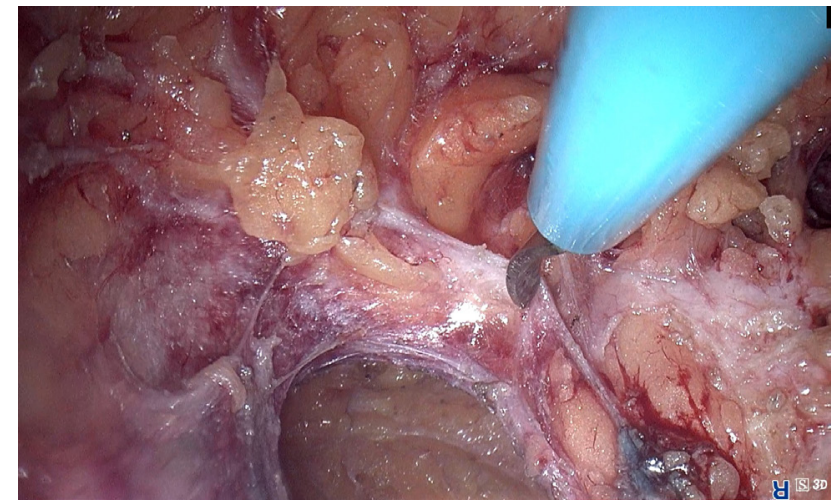

Figure 7. Skin flap dissection with fibrous septa taken down using laparoscopic curved scissors 


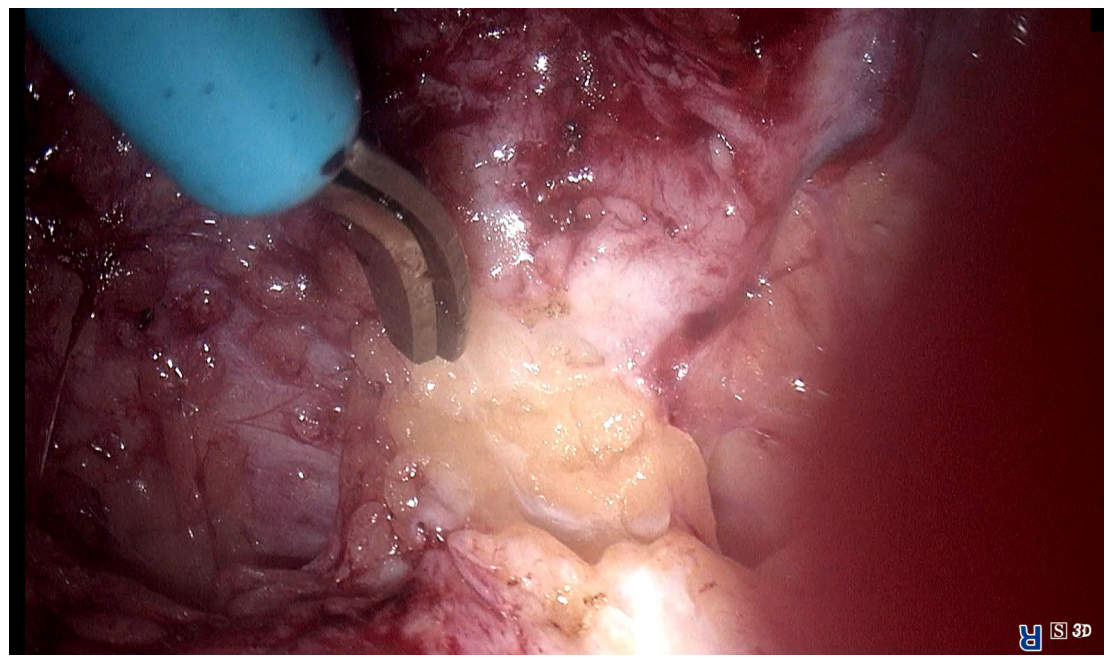

Figure 8. Thicker tissue beneath nipple areolar complex preserved to avoid nipple retraction and nipple areolar complex necrosis

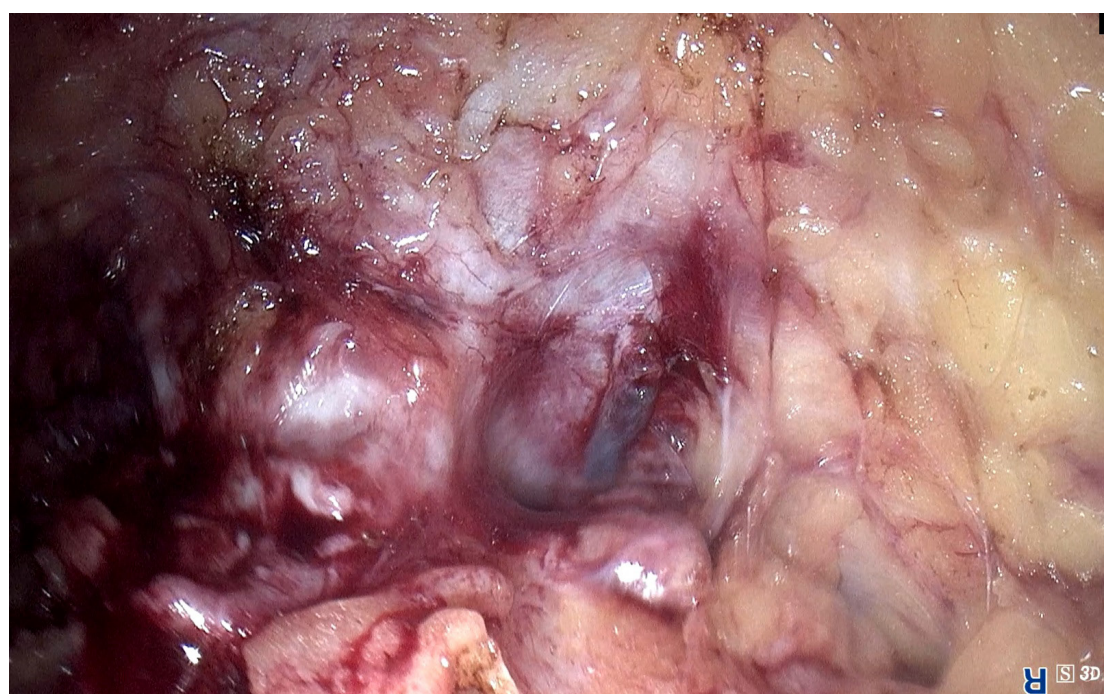

Figure 9. Blood vessel supplying nipple areolar complex can be clearly seen under three-dimensional view

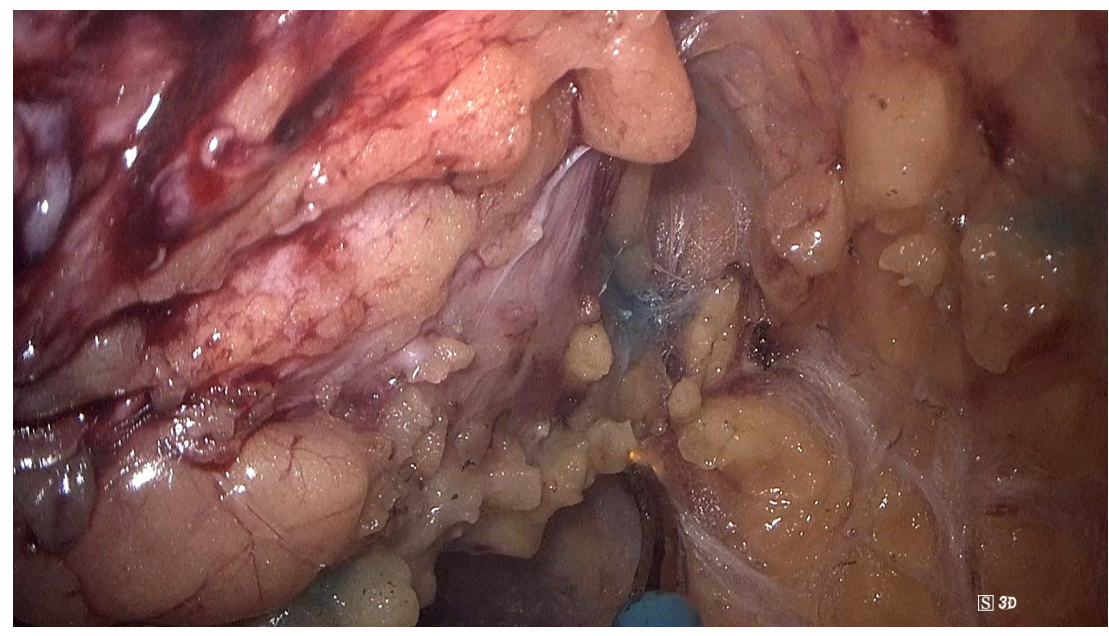

Figure 10. Extent of peripheral dissection guided by blue dye gel 

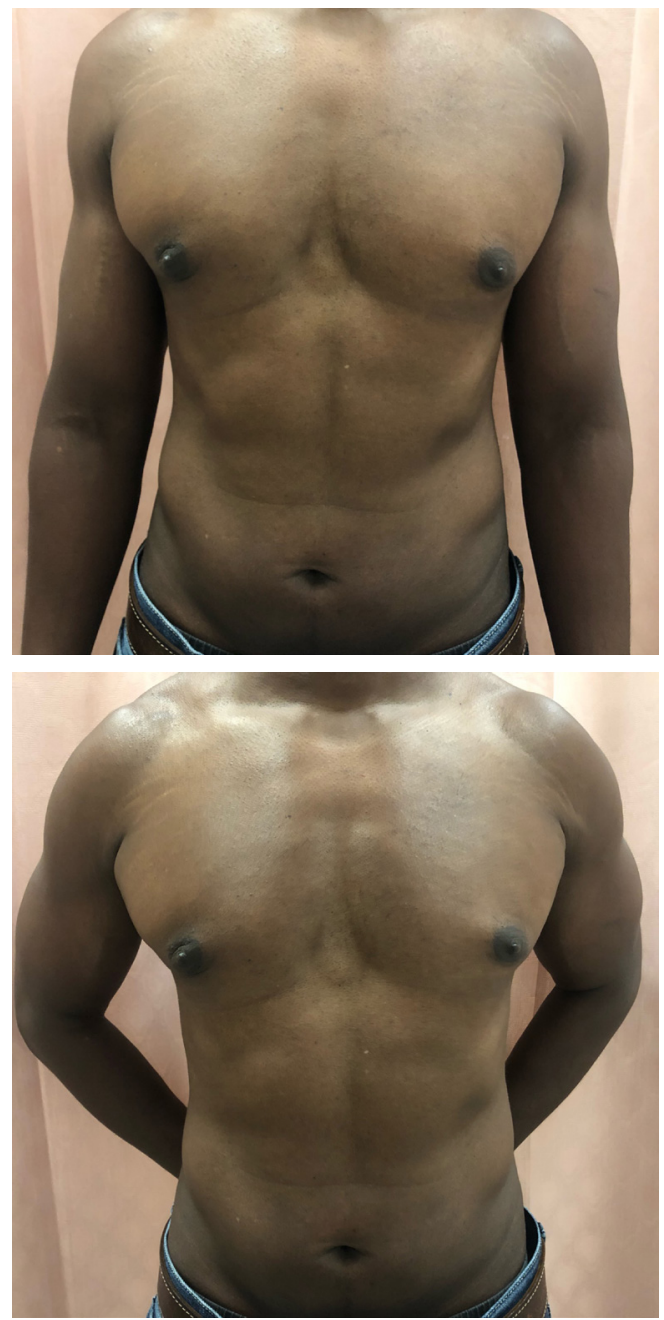

Figures 11. One-month postoperative front views showing excellent symmetry and aesthetic outcomes

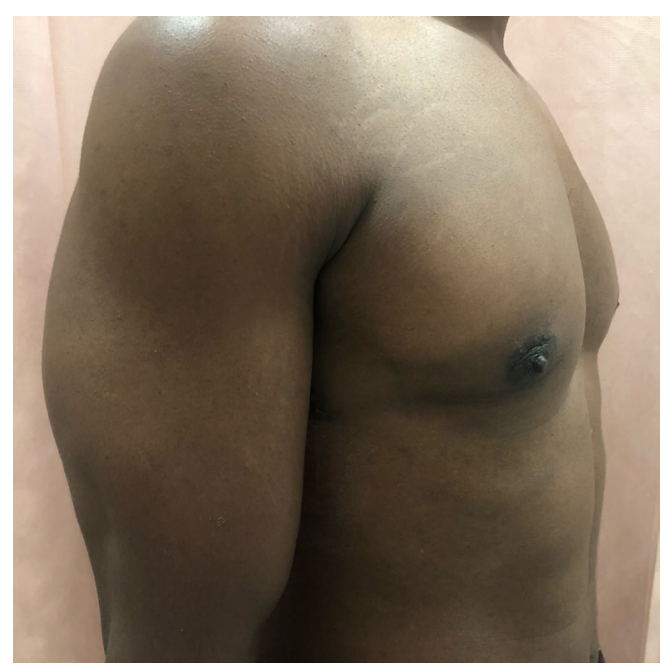

Figure 12. One-month postoperative lateral view showing hidden incision 


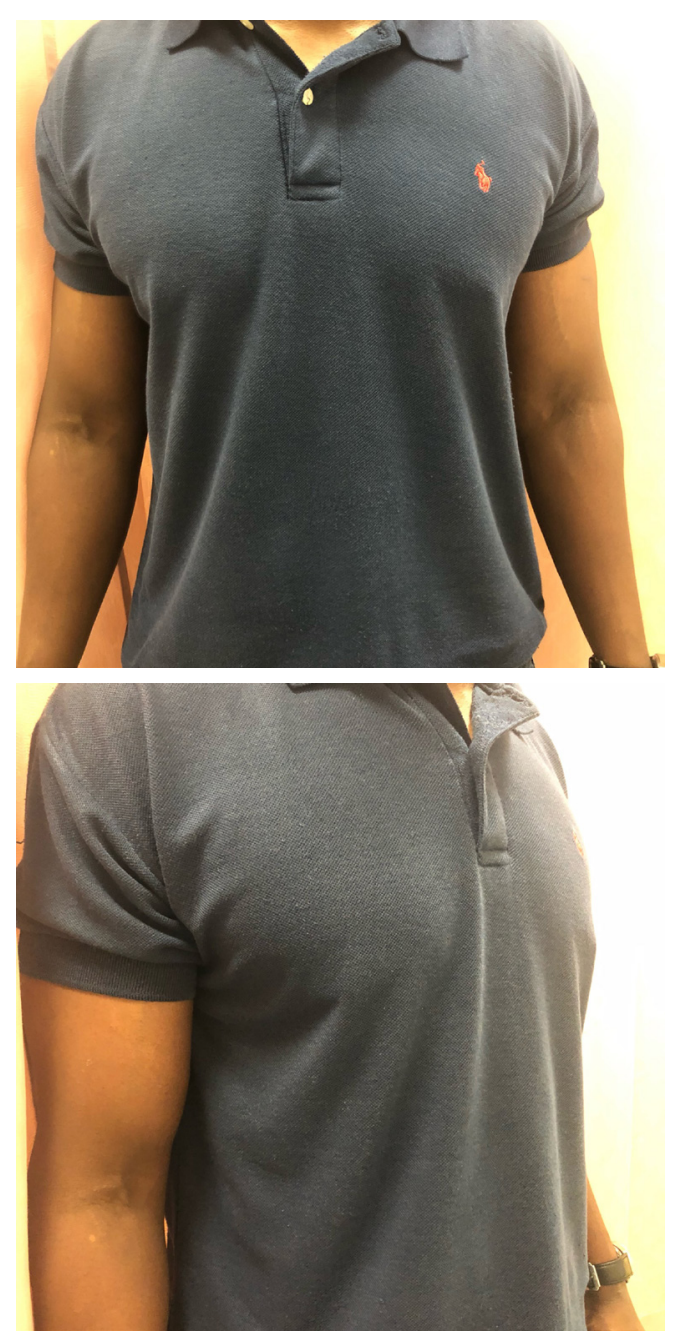

Figures 13. One-month postoperative front and lateral views (dressed) showing excellent symmetry and aesthetic outcomes

\section{DECLARATIONS}

\section{Authors' contributions}

Conception and design of the study: Mok CW, Hing JXJ

Drafting of manuscript: Mok CW

Revision and final manuscript: Mok CW, Hing JXJ, Tan SM

\section{Availability of data and materials}

Not applicable.

\section{Financial support and sponsorship}

None.

\section{Conflicts of interest}

All authors declared that there are no conflicts of interest.

\section{Ethical approval and consent to participate}

Not applicable. 


\section{Consent for publication}

Written informed consent for publication was obtained as appropriate.

\section{Copyright}

(c) The Author(s) 2019.

\section{REFERENCES}

1. Wong KY, Malata CM. Conventional versus ultrasound-assisted liposuction in gynaecomastia surgery: a 13-year review. J Plast Reconstr Aesthetic Surg 2014;67:921-6.

2. Tashkandi M, Al-Qattan MM, Hassanain JM, Hawary MB, Sultan M. The surgical management of high-grade gynecomastia. Ann Plast Surg 2004;53:17-20.

3. Fischer S, Hirsch T, Hirche C, Kiefer J, Kueckelhaus M, et al. Surgical treatment of primary gynecomastia in children and adolescents. Pediatr Surg Int 2014;30:641-7.

4. Kim DH, Byun IH, Lee WJ, Rah DK, Kim JY, et al. Surgical management of gynecomastia: subcutaneous mastectomy and liposuction. Aesthetic Plast Surg 2016;40:877-84.

5. Zhu J, Huang J. Surgical management of gynecomastia under endoscope. J Laparoendosc Adv Surg Tech A 2008;18:433-7.

6. Lai HW, Chen ST, Mok CW, Lin SL, Tai CM, et al. Single port three-dimensional (3D) videoscope-assisted endoscopic nipple sparing mastectomy in the management of breast cancer. Plast Reconstr Surg Glob Open 2019;7:e2367. 